IRA-International Journal of Management \& Social Sciences

ISSN 2455-2267; Vol.08, Issue 01 (July 2017)

Pg. no. $74-80$

Institute of Research Advances

http://research-advances.org/index.php/RAJMSS

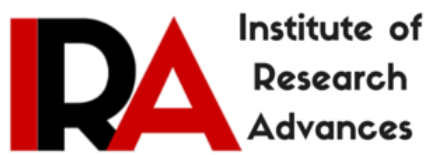

\title{
Issues Affecting the Effectiveness of Rehabilitation Programme in Oke Kura Prison, Kwara State, Nigeria
}

\author{
Kehinde Adekunle Aliyu ${ }^{1}$, Jamaludin Mustaffa ${ }^{2}$ \& Norruzeyati CheMohd Nasir ${ }^{3}$ \\ ${ }^{1,2,3}$ School of Applied Psychology, Social Work and Policy \\ Universiti Utara Malaysia, 06010 UUM Sintok, Kedah, Malaysia.
}

Type of Review: Peer Reviewed.

DOI: http://dx.doi.org/10.21013/jmss.v8.n1.p8

\section{How to cite this paper:}

Aliyu, K., Mustaffa, J., \& Nasir, N. (2017). Issues Affecting the Effectiveness of Rehabilitation Programme in Oke Kura Prison, Kwara State, Nigeria. IRA-International Journal of Management \& Social Sciences (ISSN 2455-2267), 8(1), 74-80. doi:http://dx.doi.org/10.21013/jmss.v8.n1.p8

(C) Institute of Research Advances.

\section{(cc)) BY-No}

This work is licensed under a Creative Commons Attribution-Non Commercial 4.0 International License subject to proper citation to the publication source of the work.

Disclaimer: The scholarly papers as reviewed and published by the Institute of Research Advances (IRA) are the views and opinions of their respective authors and are not the views or opinions of the IRA. The IRA disclaims of any harm or loss caused due to the published content to any party.

Institute of Research Advances is an institutional publisher member of Publishers Inter Linking Association Inc. (PILA-CrossRef), USA. The institute is an institutional signatory to the Budapest Open Access Initiative, Hungary advocating the open access of scientific and scholarly knowledge. The Institute is a registered content provider under Open Access Initiative Protocol for Metadata Harvesting (OAI-PMH).

The journal is indexed \& included in WorldCat Discovery Service (USA), CrossRef Metadata Search (USA), WorldCat (USA), OCLC (USA), Open J-Gate (India), EZB (Germany) Scilit (Switzerland), Airiti (China), Bielefeld Academic Search Engine (BASE) of Bielefeld University, Germany, PKP Index of Simon Fraser University, Canada. 


\begin{abstract}
Issues affecting the effectiveness of rehabilitation programme of the inmate, have important implications on the public safety after inmates are released from the prison. Many studies have been conducted on prisons environment effects, some investigating disciplinary methods and some exploring rehabilitation managements. Methodical evaluations of those studies, while varying greatly in exposure and method, display remarkable consistency in their overall findings. Administration and permissions, at best, show modest mean decreases in recidivism of inmate and, in some occurrences, have the differing effect and increase re-offense degrees. The way and manner recidivism effects found in studies of rehabilitation treatment, by comparison, are consistently positive and relatively large. There is, however, considerable inconsistency in those effects associated with the rehabilitation treatment, how well it is employed, and the nature of the inmates to whom it is applied. The specific sources of that inconsistency have not been well explored, but some principles for effective rehabilitation have emerged. The rehabilitation treatments generally found effective in research do not characterize existing practice of rehabilitation, and bridging the gap between research and practice residues noteworthy issues.
\end{abstract}

Keywords: effectiveness, rehabilitation, inmate, issues, conduct

\title{
Introduction
}

Like any of human endeavor, the various programmes put in place by the Nigeria Prison Service to re-socialize those imprisoned under their care have not been without restraints (Mwembo, 2009). These have made the realization of service goals of rehabilitation almost impossible to accomplish, which tends to lend credibility to the belief in some quarters that the Nigerian Prison Service is a crime industrialized haven, rather than correctional institution.

Funds are not adequately provided to the Nigerian Prison Service for the procurement of tools, machinery and other correctional materials and where it is provided no one can give account of what it was spent on. The reformative programmes are being carried out in the prisons. As a result of this, most of the times the inmates are idle. An idle mind, they say is the devil's workshop. Another challenge may be that of manpower disposition and training (Balleriaux, 2012). Few years ago, there has been a shortage of qualified manpower in Nigeria prisons workshops, cottage industries and farms, which constitute a great hindrance to correctional educational programmes. Moreover, the recent trimming has swept away the experienced technical manpower which has created a vacuum in the training and reformation of the prison inmates. Even the existing staffs that are remaining lack the required training to impart skills to the inmates in our various prisons. The subsequent effect of this is the reduction in the ability to generate revenue for government through the prison industry and level of skill acquisition among the inmates.

The Nigeria prison service as presently constituted has six directorates each headed by a Deputy ControllerGeneral of prisons. Eight zonal commands were also established, each having an Assistant Controller-General of prisons heading each. The six directorates were created in order to decentralize the functions of the prisons service with a view to ensure productivity, capacity building, speed and efficiency. All activities regarding inmate training and productivity are guided, administered and coordinated by the Directorate of Inmates Training and Productivity (Aboki, 2007). Operations of the various prisons industries, workshops, farms and market gardens, throughout the federation are controlled by the directorate (ITP). The Training and Productivity of inmates while incarcerated, the empowerment of the inmate for a better life after serving term is the ultimate which is the focus of this work, it depends largely on the educational programme delivered by the directorate of ITP (Ssanyu, 2014).

This paper therefore, intends to bring to the fore those issues that are seen to be hindering effectiveness of rehabilitation programme offered to the inmates. The concept of rehabilitation programme in the prison provides opportunity for acquisition of specific skills and knowledge. Those who attain these skills and knowledge maybe paid or be self-employed; they become wage earners and become more and more reliable and contributing as citizens if they were fully engaged (Aboki, 2007). They become assets, rather than liabilities and defendants on the general public. In this way, evaluating prison education has substantial social value to the inmate life, in that it will answer the most of the social ills in the society. People have inherent desire to be loved, cherished, cared for, feel comfortable and free without molestation. To realize these needs, one has to be able to meet many of their needs. 


\section{Objective of the Paper}

This research paper focuses on the following objectives:

i. To examine the issues affecting the effectiveness of rehabilitation programme in the prison.

ii. The paper seeks to suggest way of the issues facing Nigerian prison services.

\section{Methodology}

The research work made use of thematic analysis and content analysis through the use of books, journal publications and available sources on the internet library. This is to give a deeper understanding of the issues that surround ineffectiveness rehabilitation programme in Nigerian prison services with a view of proffering solutions.

\section{Findings}

The findings from the research would be discussed below in relation to this work on issues affecting rehabilitation. In relation to that, the focus group carried out in this study discovered in line with Bates (2005) that challenges are generated by many factors, some of which are deep-seated in character. As illustrated below in the figure through thematic analysis, the rehabilitation identified five indices of government failures which are the reasons for what limit rehabilitation in Oke Kura prison.

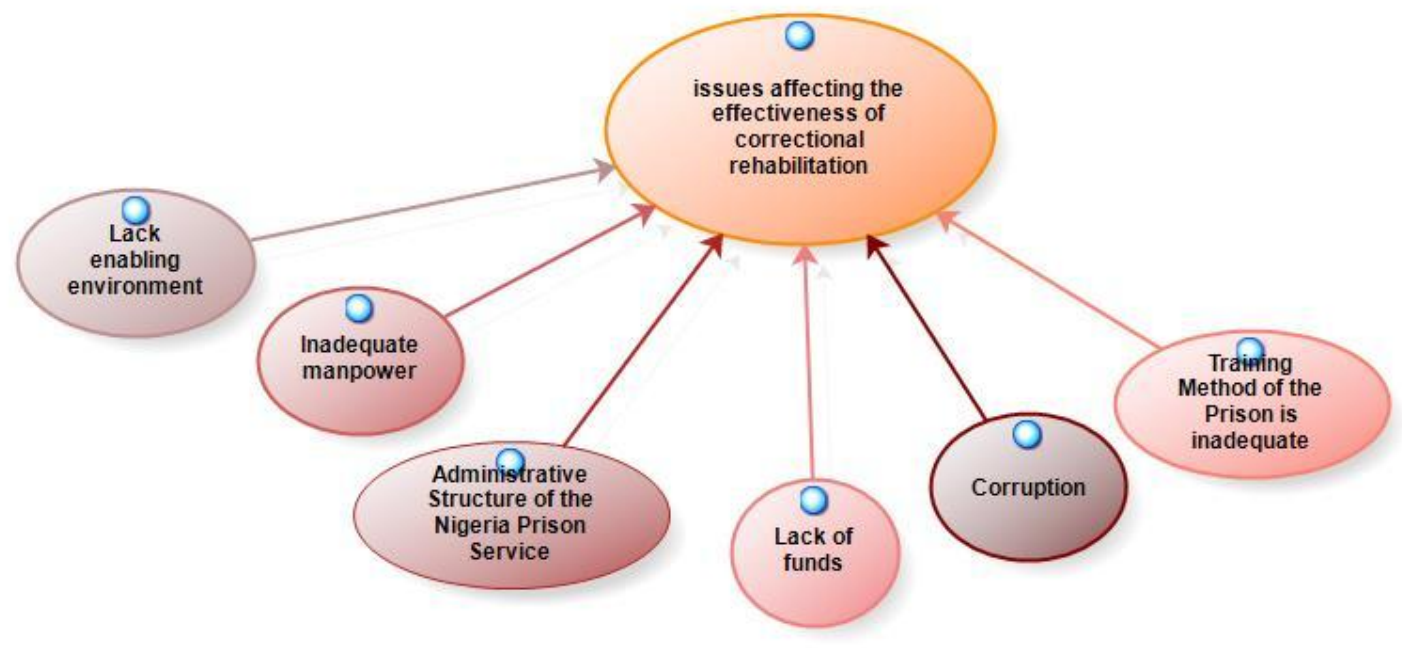

\section{Administrative Structure of the Nigeria Prison Service Problem}

The Nigeria prison service as presently constituted has six directorates each headed by a Deputy ControllerGeneral of prisons. Eight zonal commands were also established, each having an Assistant Controller-General of prisons heading each. The six directorates were created in order to decentralize the functions of the prisons service with a view to ensure productivity, capacity building, speed and efficiency. All activities regarding inmate training and productivity are guided, administered and coordinated by the Directorate of Inmates Training and Productivity. Operations of the various prisons industries, workshops, farms and market gardens, throughout the federation are controlled by the directorate (ITP). The Training and Productivity of inmates while incarcerated, the empowerment of the inmate for a better life after serving term is the ultimate which is the focus of this work, it depends largely on the educational programme delivered by the directorate of ITP (Altbach, \& Knight, 2007).

However, it is pertinent to ask what we mean by training and development. Is it the same thing as education? Then we asked again, is training also the same as development? These are important questions because answering them will have important suggestion for the way training and development of people in various institutions especially inmates in custody will come within reach. Throughout this work the following interpretation will be applied since each of the three types of learning activity is concerned, in varying degrees with attainment of knowledge, understanding, skills and approaches. But generally, many depend on schools, colleges and universities to provide the majority of the educational activities in our society (Mwembo, 2009).

This same perception was expressed by the staffs that were in the focus group. For instance, they claimed that the Nigeria prison service as presently constituted has six directorates each headed by a Deputy ControllerGeneral of prisons (Aboki, 2007). Eight zonal commands were also established, but bureaucratic bottle neck has 
made it difficult to be carried out successfully at times, concluded that, is need to create a decentralized system that will function in the prisons service with a view to ensure productivity, capacity building, speed and efficiency, all activities concerning inmate training and productivity must be carefully guided, administered and coordinated by the Directorate of Inmates Training and Productivity but it has been politicized that even people that are not qualified are been made to operate in the various prisons industries, workshops, farms and market gardens, throughout the federation. For example, it was noted that that training and productivity of inmates while in custody should be the central focus before proceeding any further; it will be useful for me to say by training and developing the inmate in a manner that is generally accepted. Similarly, Public Private Partnership." will surely strengthened any effort of Nigerian Prisons Service in ensuring the good training and development of inmates while in custody for a better re-entry to the society through rehabilitation programme.

\section{Corruption Problem}

The fact that corruption has gotten a broad consideration in the groups, and maybe, because of the way that it has been over-flagellated in the scholastic circles, corruption has gotten shifted definitions. Corruption has comprehensively been characterized as a depravity or a change from great to terrible. In particular, corruption or degenerate conduct includes the infringement of built up tenets for individual pick up and benefit (Dike, 2005). Corruption is endeavors to secure riches or influence through unlawful means private pick up at open cost; or an abuse of open influence for private advantage.

Also, corruption is a conduct which digresses from the formal obligations of an open part, as a result of private (gains) - with respect to (individual, close family, private coterie, monetary or status picks up. It is a conduct which disregards rules against the practice of specific sorts of [duties] for private (gains) - in regards to impact (Humphreys, 2010). This definition incorporates such conduct as pay off (utilization of a reward to debase the judgment of a man in a position of trust); nepotism (bestowal of support by reason of inscriptive relationship instead of legitimacy); and misappropriation (illicit apportionment of open assets for private uses (Dike, 2005). In line with scholars cited earlier corruption incorporates buy of place with cash, guarantees of office or unique favors, pressure, terrorizing, and obstruction with flexibility of whether this practice is normal. Some position are purchased, individuals lobby to be posted to where there is money even without knowledge of the office to be occupied. Corruption in office includes offers of authoritative managerial, or legal choice, or legislative arrangement. Camouflaged installment as blessings, lawful charges, livelihood, favors to relatives, social impact, or any relationship that relinquishes the general population premium and welfare, with or without the inferred installment of cash. To the officially swarmed scene (Dike, 2005), includes that corruption is a hostile to social conduct presenting inappropriate advantages in opposition to lawful and moral standards, and which undermine the powers to enhance the living states of the general population.

According to Dike (2005) one important evil of corruption is the fact that it brings about political hostility then leads to social insurgency and most times military takeovers. In view of this facts and the implications of corruption the rehabilitation programme for the inmates. But the most important thing is that poverty is both a cause and a consequence of corruption (Terwase, Abdul-Talib, Zengeni\&Terwase, 2015). The relationship is two-way: poverty leads to crime and vice versa. The association between poverty and crime occurrence has for that reason received both theoretical and empirical attention (Dike, 2005). Similarly to what this study discovered from the interviewees, there are different types of corruption include: bribery: the installment (in cash or kind) that is taken or given in a degenerate relationship. These incorporate kickbacks, tips, pay-off, sweeteners, lubing palms, and so forth. Embezzlement, this is robbery of open assets by open authorities. It is the point at which a prison official takes from inmate feeding, material, etc. In Nigeria the theft of open assets is a standout amongst the most well-known methods for monetary gathering, maybe, because of absence of strict administrative frameworks in the Nigeria system itself. This was collaborated by Humphreys, (2010) favoritism, this is a component of force manhandle suggesting an exceedingly one-sided circulation of prison posting. Be that as it may, this is viewed as a characteristic human proclivity to support companions and anyone close and trusted by the man on the seat. Due to the destructive impacts of corruption in national improvement, and given the relative constrained assets or destitution in the area, Nigerian prison service, and for sure Nigeria, suffer so much.

\section{Inadequate manpower Problem}

The first sets of descriptions were proposed by (Marsick, and Watkins, 2015) who isolated three main roles. He sees a trainer as a learning specialist, an administrator and a problem solver. Despite the awkwardness of some Nadler's descriptors, it is certainly possible to see a picture of a trainer as a person who has to combine his specialist knowledge of learning with the specific needs of the organization, i.e. in terms of its problem and who is required to perform an administrative role as part of his work. The trainer must be able to combine his specialist knowledge of learning with the specific needs of the organization to achieve the organizational goals 
and policy. A trainer must therefore be endowed with the ability to perform some specific specialized functions such as determining the training requirement, directing, planning and organizing of training activities by designing the training programmes, preparing for the training, carrying out training and then assessing the result of the training carried out.

Once an organization can recognize the importance of training and development and the role of trainers, it can then go ahead with suitable structures analyze its training needs and allocate adequate funds for the execution of training activities. Mumtaz, (2000) stated that inadequate manpower another problem or challenge may be that of manpower disposition and training. Some years ago, there has been a dearth of qualified manpower in Nigerian prisons workshops, cottage industries and farms, which constitute a great hindrance to correctional programmes. In addition, the recent downsizing has swept away the experienced technical manpower which has created a vacuum in the training and reformation of the prison inmates. Kolb, (2014) add to what he said, even the existing staffs that are remaining majority of us lack the required training to impart skills to the inmates in our various prisons. The training policy of the rehabilitation included in a range of policies dealing with human resources is prepared to do in terms of developing those concerned or involved.

\section{Lack of funds Problem}

Funds are not adequately provided to the Nigerian Prison Service for the procurement of tools, machinery and other correctional materials, for the reformative programmes which are being carried out in the prisons. As a result of this, most of the times the inmates are idle, "an idle mind, they say is the devil's workshop". Another problem or challenge may be that of manpower Disposition and Training. There has been a dearth of qualified manpower in Nigeria prisons workshops, cottage industries and farms, which constitute a great hindrance to correctional programmes (Jacintha, 2016). In addition, the recent downsizing has swept away the experienced technical manpower which has created a vacuum in the training and reformation of the prison inmates. Even the existing staffs that are remaining lack the required training to impart skills to the inmates in our various prisons. The resultant effect of this is the reduction in the capacity to generate revenue for government through the prison industry and level of skill acquisition among the inmates (Hertel, and Calcaterra, 2005).

Jacintha, (2016) Funds are not adequately provided to the Nigerian Prison Service for the procurement of tools, machinery and other correctional materials, for the reformative programmes which are being carried out in the prisons for the inmate. As a result of this, most of the times the inmates are idle (I mean doing nothing). These perceptions, was equally confirmed by the frustration-aggression theory and the relative deprivation theory according to Aboki, (2007) that they suggest that individuals become aggressive when there are obstacles (perceived and real) to their success in life. Similar frustration was also expressed by. An idle mind, they say is the devil's workshop. The resultant effect of this is the reduction in the capacity to generate revenue for government through the prison industry and level of skill acquisition among the inmates while in custody.

\section{Training Method of the Prison is inadequate Problem}

Training and development are essential to success in achieving the service goals. The role of training inmates in custody is therefore primarily determined by overall purpose of the organization or service. This provides those responsible for implementing training and development with the best possible raison deter. The stimulus for adopting a systematic approach to raining and development arises from the intensity of internal and external pressure for change in the service. The first step in a systematic approach is to devise a policy statement to act as a guide to the service's intention concerning the weight and direction to be given to training and development. The second step is to define an initial set of roles for those responsible for implementing the policy, notable trainers. The third step is to set up a suitable structure of training post and procedures, and to allocate sufficient funds to the training organization.

When we talk about training methods we are essentially discussing the means by which we intend to communicate information, ideas, skills, attitudes and feelings to learners. Thus, methods are a crucial element in the trainer's success. It is common to find methods categorized according to whatever the situation is. In consistent with the issue of discrimination and its implication on the ethnic relation among group and people, most of the ethnic group leaders interviewed alluded to it as a reason for grievances and then conflict emergence (Silberman, and Biech, (2015). This approach does not make it easy to distinguish the appropriateness of methods for communicating knowledge rather than developing skills or attitudes. That is the location and hence the context of training is of course important.

\section{Lack enabling environment Problem}

In every society the access to basic facilities like electricity, drinking water, sanitation, health care facilities and solid waste management are critical determinants of quality of life (Goble, Bhagat, Aleksejevs, Cruickshank, Michaelides, Newman, and De Roure, (2010). As important as these amenities are to the cherished existence of 
any community, most especially the inmates, on the other hand the staff of the prison, they are seriously deficient and unequally distributed in some societies, one of which is Nigeria (Iyoha, and Oyerinde, 2010). Though, imbalances in access to social amenities may be due to inefficiency in the distribution and allocation as a result of social barriers like classroom, workshop, but in the case of Nigeria, according to the staff, it is mostly as result of government failure and deliberate abandonment prison facilities all over Nigeria. This observation was equally echoed by the informants of this study as a serious source of worry and aggressive behaviours from the people. For instance, insufficiency in the instructive capacity of the detainees has prompted to further detainment among the detainees. The environment did not permit the inmate to fully express themselves since family associations are moreover a major part of the characteristics of the inmate (Aboki, 2007). The enlightening work and criminal histories of the family all impact on the inmate feelings about socialization and compositions of prison yard.

\section{Conclusion}

The severally mentioned to the insensitivity of authority in the provision of basic needs to serve as stimulants for the inmate, for that reason, most of them concluded that being in prison survivor of the fittest, but been sensitive will go a long way in ameliorating it. The study revealed that building classroom or workshop could help potentially in playing reconciliatory role as well as promoting common values among the inmate and prison staffs. Rather that emphasizing the variances among them, as it was showed the Informants want the government to be persistent in investing in the prison programme. Likewise, it was revealed that in view of the important role of social workers must also put into consideration for better remunerations, the good environment should permit the inmate and social workers to fully express themselves. The enlightening work and criminal histories of the family all impact on the inmate feelings about socialization and compositions of prison yard should be rehabilitation center.

\section{Recommendation}

1. The authority should allow the inmate to acquire relevant knowledge and skills for employment and to boost their chances of parole. The above responses are significant in terms of the contexts of the participants. As the discussion revealed that most of the prison inmates did not have knowledge and skills for employment and this, they confessed, led them to crime and the concomitant incarceration. The inmate should be given the opportunity to attend school when they were young, while motivate older ones not to dropped out because of the harsh conditions such as long distances to travel to school if it cannot be provided in the prison yard due to lack of infrastructures, the poor schooling system, lack of support to remain in school and the motivation to learn.

2. Correctional or rehabilitation personnel should be exposed to more training on how to understand and cope with the specific needs and circumstances of correctional or rehabilitation programme. Thus, all trainers and programme planners for prison rehabilitation should be given some reasonable training on elements of Andragogy, (Psychology of adult learning) as this will help them to understand the needs, problems, thus appreciate the interests of the inmate participants in rehabilitation programme.

3. Nigerian government must change from its insensitivity to issues prison rehabilitation programme must seek to identify and stimulate the inmate dormant wants and respond flexibility as interests emerge. Programme should not be limited to conventional subjects but explore other aspect. The potential participants will always like to learn what is paramount and beneficial to him. Also, there should be follow-up and motivational classes for the participants.

\section{References}

1. Aboki, E. (2007). History of Nigeria Prisons Service, an inside account. Kaduna: Bizmak publishers.

2. Aliyu, K. A., Mustaffa, J., \& Nasir, N. B. C. M. (2016). The difficulties of staff welfare IN the organization of Nigerian Prison Service (NPS) An Investigation of Oke Kura Prison, Kwara State Nigeria. Proceedings of the ICECRS, 1(1).

3. Altbach, P. G., \& Knight, J. (2007). The internationalization of higher education: Motivations and realities. Journal of studies in international education, 11(3-4), 290-305.

4. Balleriaux, C. (2012). Reformation Strategies: Conversion, Civility, and Utopia in issionary Writings about the New World, c. 1610-1690 (Doctoral dissertation, ResearchSpace@ Auckland).

5. Bates, D. (2005). Fitting linear mixed models in R. R news, 5(1), 27-30.

6. Dike, V. E. (2005). Corruption in Nigeria: A new paradigm for effective control. Africa Economic Analysis, 24(08), 1-22. 
7. Goble, C. A., Bhagat, J., Aleksejevs, S., Cruickshank, D., Michaelides, D., Newman, D.,\& De Roure, D. (2010). myExperiment: a repository and social network for the sharing of bioinformatics workflows. Nucleic acids research, 38(suppl_2), W677-W682.

8. Hagan, M. I. C. H. A. E. L. (2013). The Impact of the Rehabilitation Programmes of the Nsawam Prisons on its Inmates (Doctoral dissertation, University of Ghana).

9. Hertel, P. T., \&Calcaterra, G. (2005). Intentional forgetting benefits from thought substitution. Psychonomic Bulletin \& Review, 12(3), 484-489.

10. Humphreys, S. (2010). Theatre of the rule of law: transnational legal intervention in theory and practice (Vol. 73). Cambridge University Press.

11. Iyoha, F. O., \& Oyerinde, D. (2010). Accounting infrastructure and accountability in the management of public expenditure in developing countries: A focus on Nigeria. Critical perspectives on Accounting, 21(5), 361-373.

12. Jacintha, U. E. (2016). Information Needs of Prisoners and Resources Provision through the Prison Library in South East Zone of Nigeria (Doctoral dissertation).

13. Kolb, D. A. (2014). Experiential learning: Experience as the source of learning and development. FT press.

14. Marsick, V. J., \& Watkins, K. (2015). Informal and Incidental Learning in the Workplace (Routledge Revivals). Routledge.

15. Mumtaz, S. (2000). Factors affecting teachers' use of information and communications technology: a review of the literature. Journal of information technology for teacher education, 9(3), 319-342.

16. Mwembo, L. M. (2009). Congolese immigrant parents' perceptions about their children's education in Philadelphia. Temple University.

17. Silberman, M. L., \&Biech, E. (2015). Active training: A handbook of techniques, designs, case examples and tips. John Wiley \& Sons.

18. Ssanyu, R. (2014). Prisoner Rehabilitation in the Uganda Prison Service.

19. Terwase, I. T., Abdul-Talib, A. N., Zengeni, K. T., \& Terwase, J. M. (2015). The Psychological Trauma on Boko Haram Victims in Nigeria: Conflict Resolution Perspective. Mediterranean Journal of Social Sciences, 6(6 S4), 519. 